\begin{tabular}{lllll|}
\hline Motrivivência & Ano XX, & No 31, P. & 207-223 & Dez./2008 \\
\hline
\end{tabular}

\title{
Educação Física e Interdisciplinaridade na Educação de Infância
}

\author{
Rosana Sandri Gleutério de Souza' \\ Jucimara Rojas ${ }^{2}$
}

\begin{abstract}
Resumo
Esta pesquisa visa compreender a Educação Física como princípio pedagógico que possibilite a interdisciplinaridade no processo de aprendizagem da criança. Para esse fim, foram entrevistados oito professores de educação infantil que trabalham em escolas da cidade

de Campo Grande, estado do Mato

Grosso do Sul. A Fenomenologia sustenta o processo teórico na análise dos depoimentos. Identificamos que a Educação Física viabiliza inter-relações entre os elementos constitutivos da educação da criança

e se apresenta como caminho para fazer essa interdisciplinaridade, promovendo a interação entre os professores das diferentes disciplinas.

Abstract

This research aims to understand Physical Education as a pedagogic principle that enables the application of interdisciplinarity in the children's learning process. The eight teachers interviewed work with children's education in schools in the city of Campo Grande, in the state of Mato Grosso do Sul. Phenomenology supports the theoretical process in the idiographic and nomothetic analyses of the interviewees' statements. It was possible to identify that Physical Education enables inter-relations between the constitutive elements in children's education; it is also a means to construct interdisciplinarity in Children's Education, with the promotion of interaction among teachers from different subjects.
\end{abstract}

Palavras-chaves: Interdisciplinaridade; Educação Física; Educação da criança

Keywords: Interdisciplinarity; Physical Education; Children's Education.

1 Mestre em educação pela UFMS - Professora de Educação Física do Colégio Militar de Campo Grande. Contato: rosanasandri@pop.com.br

2 Doutora em Educação - UFMS. Contato: jjrojas@terra.com.br 


\section{Introdução}

A proposta de investigação da pesquisa pauta-se sobre a questão interdisciplinar que o "fazer" do professor de Educação Física pode propiciar, no contexto das instituições de Educação de infância. Interdisciplinaridade que tem como princípio norteador à atitude de abertura do ser às novas práticas, logo a novas ações e participações. Como nos diz Rojas (1998):

A interdisciplinaridade [...]. Não propõe a eliminação da disciplinaridade, mas a questiona e a relê em um contexto mais amplo. Desvela que o conhecimento não resulta de um simples contemplar, nem apenas de um refletir; mas de um agir, de um analisar o que é criado... De uma atitude... (ROJAS, 1998, p.29)

Sendo assim, acreditamos que o professor de educação física pode e deve apoiar-se na especificidade pedagógica da educação física, como área de conhecimento que trata das práticas corporais de movimento, para estabelecer parcerias em projetos coletivos de ensino, para assumir dentro do processo de educação para a criança e com a criança, uma atitude interdisciplinar.

Desde a publicação da LDB, as discussões no meio acadêmico sobre a inserção da Educação
Física na educação infantil têm se tornado cada vez mais presentes, buscando fundamentar a sua importância neste contexto escolar. Nos dias atuais, ainda que muito mais na teoria do que na prática, chegamos a uma Educação Física definida como área de conhecimento estruturada, pensada e justificada como disciplina que contém sua identidade e especificidade e, portanto, uma proposta curricular, conteúdos e objetivos a alcançar, em todos os níveis escolares, inclusive com conteúdos específicos para as crianças pequenas.

O que se observa, porém segundo Tani (2001) é um distanciamento entre a teoria e a prática. Apesar das pesquisas acadêmicas acerca da importância da Educação Física na educação da criança avançarem significativamente, a prática do profissional na escola não tem sofrido grandes mudanças.

Ainda sobre esta questão Ferraz (2001) nos acrescenta que podemos encontrar atualmente, na Educação Física infantil, profissionais atuando nas escolas de três maneiras distintas: realizando seu trabalho sem sequer participar das reuniões pedagógicas da escola, utilizando a Educação Física como "meio" para atingir objetivos de outras áreas como a alfabetização, por exemplo, e numa relação de interdependência, preservando sua 
especificidade e integrando-se às demais áreas do conhecimento na totalidade do projeto pedagógico da escola.

É esta terceira relação que mais nos interessa. Pois além de contribuir para o desenvolvimento da criança a Educação Física pode colaborar para o entrosamento e a interação humana, quando se coloca no patamar de atitude interdisciplinar.

Logo, o objetivo da pesquisa foi compreender a interdisciplinaridade e seus fundamentos na educação da criança, pensando a Educação Física como suporte pedagógico que possibilite tal interdisciplinaridade. Lançar um olhar para a ação do professor de Educação Física e, principalmente, mostrar essa ação em atitude, como parte integrante de um projeto pedagógico da escola.

Tal interdisciplinaridade sustentará uma formação capaz de promover um verdadeiro desabrochar da criança, pressupondo a utilização de um corpo que age, gesticula e se movimenta, como fundamental para a aprendizagem de um modo geral. $\mathrm{O}$ fazer motor é envolver-se, concentrar-se, estar atento, realizar operações mentais com os conceitos expostos e necessários de todos os tipos. Envolver-se é agir... agir com o corpo.

\section{Educação Física e Interdisci- plinaridade}

Buscando a melhoria da aprendizagem da criança, acreditamos na interdisciplinaridade como suporte necessário para proposição de atividades diferenciadas na educação da criança, tendo o movimento corporal, os gestos, a motricidade, a valorização do brinquedo e da brincadeira, também cheios de movimento de forma natural, como sustentáculo de desenvolvimento. Assim pensamos em uma criança por inteiro, em uma educação por inteiro, interdisciplinar.

Nossa perspectiva de busca de interdisciplinaridade como uma ação transformadora centra-se no reconhecimento do corpo como vivência do ser criança, como presença fundamental no ato educativo. Por sermos profissionais da educação Física, profissionais que pensam o corpo. Nesse raciocínio pensamos que a escola deverá perpetuar o encontro entre o mundo da razão e o mundo da corporalidade, percebendo que corpo e razão não estão dissociados, mas integrados, numa totalidade, em um processo de interação de um Ser que precisa ser reconhecido de maneira integral.

Abrimos assim os horizontes para a efetivação de um trabalho interdisciplinar a ser realizado pelos professores. A partir da atitude, da 
disposição para rever o velho e transformá-lo em novo, da ousadia dos educadores, pode ser um "comprometimento com a totalidade" (FAZENDA, 2006b, p. 91), o fazer para a criança de uma corporeidade educativa, qualitativa, uma prática inovadora, diferente, que foge do pronto, repetido ou uniforme:

Abundam no senso comum e na prática das escolas, relatos e posicionamentos que afastam as questões relativas ao corpo (a motricidade), das relativas à mente (cognição). Esta visão quando mantida no fazer daqueles que atuam na escola, transformam o ambiente de aprendizagem em um local de sofrimento para os pequenos, distante da realidade, do interesse e dos atrativos infantis.

Consideramos a motricidade como forma de expressão, ação e comunicação que funciona como evidência de equilíbrio afetivo e inteligência. O desenvolvimento dessa forma de manifestação humana se explica a partir da interação do ser com o mundo. A evolução das faculdades perceptivo-motoras, que trazem consigo a possibilidade de agir sobre o mundo é o motor do desenvolvimento infantil. (MATTOS; NEIRA, 2007).

Acreditamos que ao desenvolver sua motricidade brincando, a criança experimenta o mundo, numa interação que possibilita descobertas e conhecimentos sobre si mesma, sobre o outro e sobre o mundo que a rodeia. Assim, a ludicidade deve estar presente não só nas aulas de Educação Física, mas também nas atividades da sala de aula permitindo a manifestação da espontaneidade da criança traduzida em gestos, falas e movimentos que a criança expressa de forma prazerosa.

Diante da importância do brincar para o desenvolvimento do ser pequeno, pensamos, então, que os professores da criança devem pautar-se numa ação educativa que revele percepção e criatividade, numa parceria que encontre na ludicidade e motricidade próprias da criança possibilidades de descobrir o novo, um novo jeito de ensinar, pautadas na busca pela interdisciplinaridade.

Pensamos que a proposição de uma concepção lúdica para a construção do processo do aprender possibilita inter-relações possíveis entre os elementos constitutivos das aulas de Educação Física e das demais atividades propostas na educação da criança. Segundo Mattos e Neira (2007) o que vemos na atualidade na educação de infância é uma dedicação quase integral das professoras ao momento de alfabetização. Nesse esforço, tememos que outros elementos colaboradores do processo, como é o caso da Educação Física, fiquem relegados à terceiro ou quarto planos. 
Pensamos então em unir tudo isso: o movimento, a escrita, a atividade lúdica e a leitura, ciências, matemática, como exemplo de uma possibilidade de interdisciplinaridade, de habitar o contexto e permitirse espelhar em ação, no fazer do professor de Educação Física, evidenciando jogos e brincadeiras que contemplem o desenvolvimento da criança em sua totalidade.

Caberá na educação infantil, a estruturação de um trabalho com o corpo abrangendo as características acima mencionadas: a vinculação do movimento a intenções, raciocínios e planos de ações elaborados; as atividades com significado, com o concreto, com o real, com o interesse daquele que é o mais importante no processo, o educando. (MATTOS; NEIRA, 2007).

A interdisciplinaridade da Educação Física na escola permitirá encontrar novos caminhos para a prática pedagógica, uma espécie de libertação, de desafio, que leve a criança a movimentar-se de forma natural, interagindo consigo mesma e com o ambiente, obtendo dessa forma o controle motor que favoreça o seu desenvolvimento pleno e autônomo.

\section{Um caminhar em pesquisa: metodologia}

A Fenomenologia é o estudo da essência em que, para se chegar à "essência das coisas", se faz a descrição das experiências. Seguindo a linha fenomenológica as análises ideográfica e nomotética, nos possibilitam momentos de percepção e rigor na análise dos depoimentos de nossos sujeitos.

Para a realização da pesquisa utilizamos informações obtidas junto a oito educadores da educação de infância, sendo quatro professores de Educação Física, e quatro professoras de sala de aula.

Optamos por escutar o professor de Educação Física e também, o professor de sala de aula, pois, a proposta de investigação de nossa pesquisa pauta-se sobre a questão interdisciplinar que o "fazer" do professor de Educação Física pode propiciar, no contexto das instituições de Educação de infância de Campo Grande. Pretendemos pensar a Educação Física como princípio pedagógico que possibilita a interdisciplinaridade. Buscamos a evidência de uma atitude interdisciplinar, que demonstre parceria, cooperação, dedicação e humildade em trocar com outros saberes e com os outros profissionais, a trilha de se produzir uma educação diferenciada para a criança.

Os sujeitos escolhidos convivem com o processo de trabalho com a criança e, muitas vezes, sentem as dificuldades da comunicação entre as pessoas e os 
saberes que envolvem o seu fazer enquanto professor. Percebemos a importância de saber o que pensam o professor da quadra e o professor da sala, ambos os profissionais na colaboração da presente pesquisa, para que ela tivesse realmente uma consistência, principalmente no saber construído sobre a interdisciplinaridade na prática docente.

Logo, seguindo esse pensamento, a concepção de interdisciplinaridade da Educação Física na educação de infância foi exposta à medida que as falas dos sujeitos se manifestaram em diálogo. O encontro com tais profissionais foi feito de maneira informal, em que percebemos um interesse em participar da pesquisa, compartilhando dúvidas e expectativas. Ocorreu em clima de total liberdade em que os professores responderam à pergunta, sem limite de linhas ou tempo para sua fala ou escrita. Eles puderam exprimir a sua opinião com muita tranquilidade.

Os sujeitos foram nomeados pelas letras do alfabeto de A até $\mathrm{H}$ para melhor organização da pesquisa. $\mathrm{O}$ quadro a seguir apresenta um dos momentos do processo de análise: o momento da redução fenomenológica em que destacamos aqueles trechos das falas dos sujeitos, que mais se sobressaíram, sempre norteadas pela nossa pergunta: Porque a Educação Física pode fazer a interdisciplinaridade na educação de infância?

\section{Quadro: Asserções dos sujeitos}

\begin{tabular}{|c|c|}
\hline ASSERÇÕES DOS SUJEITOS & SUJEITO \\
\hline $\begin{array}{l}\text { 1. Por ser uma aula mais dinâmica e mais lúdica, podemos ter uma } \\
\text { interação. } \\
\text { 2. A professora de educação física me auxilia. }\end{array}$ & A \\
\hline $\begin{array}{l}\text { 3. Podemos trabalhar situações que não conseguimos resolver em } \\
\text { sala. } \\
\text { 4. Podemos trabalhar a lateralidade seqüência numérica, direita/ } \\
\text { esquerda, alto/baixo que influencia em atividades propostas em } \\
\text { sala de aula. } \\
\text { 5. A educação física deva ser trabalhada em conjunto com o } \\
\text { professor de sala. } \\
\text { 6. Dessa maneira a criança aprende brincando. }\end{array}$ & B \\
\hline $\begin{array}{l}\text { 7. Através da interdisciplinaridade a(o) professora de Educação } \\
\text { Física pode direcionar suas atividades interligadas com a } \\
\text { professora titular. } \\
\text { 8. A interdisciplinaridade facilita o trabalho em sala, uma vez } \\
\text { que se trabalha com atividades e brincadeiras a lateralidade, o } \\
\text { espaço, coordenação motora grossa e fina, necessária para o } \\
\text { desenvolvimento da escrita e da leitura. }\end{array}$ & C \\
\hline
\end{tabular}




\begin{tabular}{|c|c|}
\hline ASSERÇÕES DOS SUJEITOS & SUJEITO \\
\hline $\begin{array}{l}\text { 9. As aulas de educação física visam à construção do } \\
\text { conhecimento e seu desenvolvimento. } \\
\text { 10. As aulas de educação física trabalham dentro do universo } \\
\text { lúdico e podem contribuir muito no desenvolvimento de outras } \\
\text { disciplinas. }\end{array}$ & $\mathrm{D}$ \\
\hline $\begin{array}{l}\text { 11. A psicomotricidade associada ao movimento e descoberta do } \\
\text { corpo é um instrumento de aprendizagem para a criança. } \\
\text { 12. O movimento corporal é uma linguagem que a criança se } \\
\text { expressa e se integra a outras linguagens como a leitura e } \\
\text { escrita, a fala, o desenho, raciocínio lógico. } \\
\text { 13. A Educação Física deve permear todo o trabalho pedagógico } \\
\text { por meio de jogos, brinquedos e brincadeiras envolvendo } \\
\text { Português, Matemática, Ciências. } \\
\text { 14. A Educação Física deve frisar conceitos, como orientação, } \\
\text { equilíbrio, agilidade, desenvolvimento motor, essenciais para } \\
\text { que a criança construa conhecimentos da matemática, língua } \\
\text { portuguesa ciências. } \\
\text { 15. O movimento é essencial para o desenvolvimento integral da } \\
\text { criança. }\end{array}$ & $\mathrm{E}$ \\
\hline $\begin{array}{l}\text { 16. A Educação Física pode e deve interagir com as demais } \\
\text { disciplinas. } \\
\text { 17. Em várias atividades recreativas e lúdicas é possível desenvolver } \\
\text { a aprendizagem de geografia, matemática, raciocínio lógico e } \\
\text { cognitivo. } \\
\text { 18. A interdisciplinaridade presente favorece o bom } \\
\text { desenvolvimento da aprendizagem das crianças. }\end{array}$ & $\mathrm{F}$ \\
\hline $\begin{array}{l}\text { 19. O movimento é a principal forma de expressão da criança } \\
\text { pequena. } \\
\text { 20. Quando ensinamos jogos e brincadeiras estamos também } \\
\text { ensinando regras, noções de espaço, de tamanho, de cores, } \\
\text { etc.... } \\
\text { 21. A Educação Física pode fazer a interdisciplinaridade na } \\
\text { educação da infância na medida em que ela possibilita à criança } \\
\text { o aprendizado a partir do seu próprio corpo. } \\
\text { 22. Entendendo-se como ser humano e dotada de um corpo a } \\
\text { criança interage com os conhecimentos sobre a natureza, sobre } \\
\text { o corpo humano, sobre a matemática a história. }\end{array}$ & G \\
\hline $\begin{array}{l}\text { 23. A Educação Física tem como meta/objetivo contribuir no } \\
\text { desenvolvimento integral da criança. } \\
\text { 24. A interdisciplinaridade se faz com cooperação e diálogo entre as } \\
\text { disciplinas, para que trabalhem na busca de um mesmo fim. }\end{array}$ & $\mathrm{H}$ \\
\hline
\end{tabular}


Sendo assim, as asserções apresentam os aspectos mais importantes, mais significativos, do fenômeno estudado. As convergências demonstram os aspectos que embasam a estrutura geral e as divergências apresentam as reações individuais ao fenômeno. As Categorias Abertas, então, representam os resultados de toda a ação do investigador na prática da redução fenomenológica, constituindo-se em subsídios para a análise. Agruparmos as temáticas convergentes e retiramos as Categorias Abertas, fazendo uma redução, facilitando o caminho da hermenêutica. Chegamos a quatro categorias: INTERAÇÃO, LUDICIDADE, MOTRICIDADE E APRENDIZAGEM. A partir dessas palavras(categorias) realizamos nossa interpretação.

\section{A guisa de conclusão: Herme- nêutica de um momento.}

Procuramos traduzir e dar sentido às categorias abertas extraídas das análises percorridas pela metodologia, referindo-se às nossas interrogações quanto à interdisciplinaridade da Educação Física na educação de infância: Interação, Ludicidade, Motricidade e Aprendizagem, categorias essas, retiradas das asserções dos depoimentos de nossos sujeitos e reduzidas, fenome- nologicamente, mostram-se bastante elucidativas quanto aos aspectos estudados junto à pesquisa.

Compreender tais categorias nos proporciona evidenciar possibilidades para a interdisciplinaridade no dia a dia da escola, possibilitando novos olhares para novas dimensões, novos caminhos para o Educador de Infância.

Buscamos, então, ao interpretar os achados, as vivências, o percurso de toda a pesquisa, dar um significado que ultrapasse o real, o jogo, as regras, o convencional. Apontar um sentido maior à interdisciplinaridade na educação de infância, com possibilidades de transcender e extrapolar as barreiras do velho, do já posto e acabado. Para construir novos momentos, inovando práticas e concepções.

Em nosso estudo, realizado com oito educadores de infância, por meio de conversa informal e recolha de depoimentos escritos, observamos e constatamos a presença do corpo no aprender infantil. Corpo presente nas ações diárias, conduzindo as vivências e a formação da criança. Corpo que não se restringe as aulas de Educação Física, mas que está presente como linguagem, na fala, gestos, expressões, leitura, escrita. Corpo que brinca, mesmo quando não pode, mesmo que escondido e, quando pode, se encanta e explode em energia e 
vibração, num aprender cheio de alegria, numa vivência carregada de sentido, pois representa prazer e encanto numa vivência completa, interdisciplinar.

Todos os educadores entrevistados trazem em seu depoimento de maneira explícita ou implícita a "INTERAÇÃO" que, segundo Fazenda (2002c) é requisito fundamental para o trabalho interdisciplinar. Percebemos nas falas descritas uma interação presente na intenção de ajuda mútua e na interação dos conteúdos que se propõe em atividades para a criança, mas inexistente na forma de projetos coletivos.

Ainda se vê a proposição de atividades pelo professor de Educação Física que integram conteúdos das outras disciplinas, visando a leitura, a escrita, matemática, ciências e o pedido de ajuda dos professores de sala para que os professores de Educação Física, dêem conta das questões relativas ao corpo, ao desenvolvimento de capacidades motoras que influenciam na sala de aula.

Nas falas dos professores se evidencia um: "você faz isso na quadra para eu fazer isso na sala", não vemos, portanto, a ação conjunta dos educadores da criança em projetos inovadores que configurem uma atitude interdisciplinar.
Vemos presente uma interdisciplinaridade em relação aos conteúdos, nas falas dos professores de Educação Física, que evidenciam as possibilidades de jogos e brincadeiras que desenvolvam os conhecimentos da matemática, da geografia e das ciências, por exemplo. Porém, vemos a timidez no trabalho em parceria. Vemos que os professores sentem a necessidade de trabalhar juntos, de planejar juntos, mas, quando o fazem, ainda deixam o corpo por conta da Educação Física. Vemos assim, que a Educação Física na educação infantil mostra-se como possibilidade de eliminação das barreiras entre as disciplinas, porém, percebemos que há necessidade de eliminação das barreiras entre as pessoas, para um trabalho realmente interdisciplinar.

Fazenda (2002) já nos mostra que mais difícil do que a eliminação de barreiras entre as disciplinas é a eliminação de barreiras entre as pessoas, produto de preconceito, falta de formação adequada, e comodismo. Esta tarefa árdua demandará a superação do velho e a "instalação de uma nova pedagogia, a da comunicação." (FAZENDA, 2002, p. 57). Será exeqüível, na medida em que se instaurar uma formação de professores voltados para a sensibilidade, a criação e a imaginação. A interdisciplinaridade será possível, pela participação pro- 
gressiva em um trabalho de equipe que vá consolidando uma atitude diferente, que busque uma interação entre a teoria e a prática, deixandose viver e exercer o novo

A parceria que se estabelece entre os sujeitos é fundamental na prática interdisciplinar, vimos, em nossos sujeitos a presença de uma necessidade de troca, presente nos apelos de ajuda ou no reconhecimento da necessidade de planejar juntos. Percebemos a dificuldade, porém, a intenção de estabelecer parcerias, de estabelecer o diálogo na busca pela resolução dos problemas encontrados em sala de aula.

$\mathrm{O}$ ensino interdisciplinar nasce da proposição de novos objetivos, novos procedimentos, em que primeiramente é necessária a supressão do monólogo e a instauração de uma prática dialógica. (FAZENDA, 2002). Um trabalho em parceria e o diálogo levam à "Interação"; categoria aberta encontrada nos depoimentos de nossos sujeitos, evidenciando a possibilidade de uma proposta interdisciplinar da Educação Física, na educação infantil como possibilidade de incitar o diálogo entre formas de conhecimento, e nessa busca a possibilidade de interpenetração entre elas. Entendendo-a como cumplicidade, o que implica em participação e colaboração entre o professor de Educação Física e os demais professores da criança.

Para que isto ocorra, a afetividade e a ousadia deverão se combinar em uma prática diferenciada, no fazer voltado para a criança. Humildade, coerência, espera vigiada, respeito e desapego - princípios da teoria da interdisciplinaridade deverão se combinar na prática, levando às trocas intersubjetivas, às parcerias, que se configuram como fundamento básico da ação interdisciplinar.

Pensar na interdisciplinaridade como processo de integração recíproca entre várias disciplinas e a Educação Física, rompendo estruturas de cada uma delas para alcançar uma visão unitária e comum do saber, trabalhando em parceria é, sem dúvida, uma tarefa que demanda um grande esforço de todas as partes envolvidas no processo. O pensar interdisciplinar exige o rompimento de uma série de obstáculos.

Entre esses obstáculos, destacamos a tendência fragmentadora e desarticulada do processo de construção do conhecimento, que colabora com a divisão do pensamento e do conhecimento, coloca o corpo e o aprender desarticulados, em um saber parcelado que, conseqüentemente, acarreta prejuízos para a criança.

Pensamos a interdisciplinaridade como aspiração de um 
ensinar-aprender mais felizes, como entendimento de uma nova forma de institucionalizar a produção do conhecimento nos espaços da educação infantil e na articulação de novos paradigmas curriculares em que, na comunicação do processo, haverá de receber a linguagem corporal da criança na determinação do domínio das investigações, na pluralidade dos saberes, nas possibilidades de trocas de experiências e nos modos de realização da parceria.

A "LUDICIDADE", presente nos discursos de sete dos educadores entrevistados demonstra que a Educação Física, na sua prática, ao remeter ao papel do brincar oportuniza à criança novas formas de aprendizagem, mais dinâmicas e prazeirozas, concretizando assim, oportunidade ímpar para a prática interdisciplinar. A recreação e os jogos oportunizam à criança, durante a realização das atividades, experimentar, descobrir, inventar, exercitar e conferir suas habilidades. Ao brincar, a criança estimula a curiosidade, a iniciativa e a auto-confiança, assim poderá melhorar o nível da aprendizagem, o desenvolvimento da linguagem do pensamento e da atenção.

Tendo em vista que o comportamento lúdico contribui para a aquisição de habilidades de cada domínio do desenvolvimento, o ato de brincar torna-se indispensável a qualquer proposta educativa para a criança. Sendo assim, pensamos que a Educação Física, ao desenvolver ludicamente as habilidades básicas tais como correr, saltar, pular, balançar, equilibrar, escorregar, rastejar, cair, puxar, empurrar, sentar, explorar, observar, esconder, ordenar, manipular, e muitas outras, estará contribuindo para o crescimento intelectual, social, e motor da criança.

O brincar como linguagem fundamental na infância, evidencia o mundo humano e significativo da criança. Os jogos motores organizados, em particular, constituem precioso momento para a percepção da personalidade infantil. Para tanto precisamos observar o comportamento dos pequenos antes, durante e depois da realização do jogo. Nele observam-se a apetência, o gosto, o interesse e o entusiasmo da criança sem interrogatórios. É o momento, por excelência em que observamos a conduta infantil espontânea e, a partir daí podemos oferecer os melhores elementos para estimular suas capacidades.

Pensamos então que a "Ludicidade" pode proporcionar um caminho, para trabalhar interdisciplinarmente, a Educação Física e as demais disciplinas. Por meio de jogos motores, educativos e da recreação, podemos estabelecer 
ações que facilitem o processo de educação da criança, na ação educativa que revele percepção e criatividade, numa parceria que encontre no trabalho conjunto dos professores, possibilidades de descobrir um novo jeito de ensinar. Um jeito que encontre no corpo da criança, no seu agir, gesticular e movimentar, os fundamentos para seu pleno desenvolvimento.

Os educadores entrevistados apontam que a interdisciplinaridade da Educação Física na educação infantil está ligada à "MOTRICIDADE" da criança. O movimento, para a criança, é a sua primeira linguagem. A escola, portanto, deve adequar seus procedimentos e conteúdos às características do desenvolvimento infantil, abrangendo os domínios cognitivos, motores e afetivos, ou seja, a criança deve ser vista na sua totalidade; e a motricidade, nesse caso, não pode ser entendida como algo isolado, pois é pelo movimento que a criança entra em contato com o ambiente que a cerca, explora objetos e se comunica com o outro.

O movimento é um importante elemento para o desenvolvimento da cultura humana. A criança empresta seu corpo ao mundo e transforma-o em pensamento; brincando, apropria-se da cultura, estabelecendo relações sociais com os outros. Ao se mo- vimentarem as crianças expressam sentimentos, emoções e pensamentos, ampliando as possibilidades de aprendizagem.

Entendemos que a função da escola não é apenas querer que as crianças aprendam a fazer, mas que aprendam a fazer e a compreender o que estão fazendo e o porquê de cada ação. Temos claro que os movimentos da criança carregam a dimensão de integrar emoções, contatos sociais e relações. O cotidiano tende a separar o movimento corporal de outras dimensões, esquecendo a importância do brincar, da emoção do prazer e, principalmente, de ser "criança".

Portanto, é fundamental tratar a questão do movimento atrelado à construção do universo infantil, rompendo com a idéia de que o movimento impede a concentração e a atenção das crianças, ou seja, que o movimento prejudica a aprendizagem das crianças. Pelo contrário, pensamos que integrar conhecimentos das diversas disciplinas em atividades cheias de movimento e ludicidade é um caminho possível e agradável para o aprender infantil.

Para a criança se desenvolver de maneira plena, precisa ter espaço para se expressar livremente. As aulas de Educação Física na Educação Infantil poderão ser, também um meio para que ocorra 
este desenvolvimento, pois proporcionam à criança a capacidade de exercitar seu pensamento, sua memória e de refletir sobre sua prática. Para Rabinovich (2007) estas aulas devem ser vinculadas às áreas de conhecimento trabalhadas em sala, ou seja, a criança poderá realizar uma brincadeira no pátio e depois, representá-la no papel por meio de desenho, pintura, colagem, recorte ou outras técnicas. Na realização dessa atividade, o aluno recorre à transição do real (aulas práticas) para o simbólico (representação).

A Educação Física, assim, tem um papel importante quando utiliza o maior recurso didático que possui: o corpo nas suas diversas dimensões. Na educação da criança, a ação motora e a ação mental estão de tal forma associadas que examinar um desses aspectos isoladamente causaria graves prejuízos, não só para a aprendizagem escolar, mas para todo o desenvolvimento da criança.

O corpo é o primeiro instrumento de pensamento da criança no seu diálogo com o mundo. A criança investe em situações significativas e na infância o significado depende, sobretudo, da ação corporal. Entre os sinais gráficos da língua escrita e um mundo concreto, por exemplo, existe um intermediador, muitas vezes esquecido, que é a ação corporal. O corpo não deve estar vinculado apenas por um caráter biológico de manutenção da saúde e higiene, mas representar a maneira de ser do indivíduo, relacionando-se com as funções cognitivas. (MATTOS; NEIRA, 2007).

Dessa maneira a Educação Física na Educação Infantil, ao utilizar-se fundamentalmente das ações corporais, amplia a participação do aluno e transforma suas ações pedagógicas, favorecendo sua presença como ser atuante e que participa e se envolve. O corpo é eixo comum na prática da ação pedagógica infantil é porta-voz da criança. Está presente na quadra, no pátio e também na sala de aula, portanto, pode e deve ser utilizados como veículo de aprendizagem e ações inovadoras por todos os educadores da criança.

De uma maneira geral, em todos os ciclos de aprendizagem, existem pontos de interseção entre a Educação Física e as demais disciplinas, que podem ser explorados incansavelmente. Cabe aos professores da criança, em conjunto, identificar esses pontos, adaptá-los ao nível de conteúdo e de dificuldade, intermediá-los e utilizá-los na aprendizagem, adaptá-los para o pátio e para a sala de aula, apresentando sua aplicabilidade, criando e inovando formas de ensinar.

Segundo Almeida (1988), a Educação Física, integrada às 
demais ciências, coordena um trabalho de reestruturação do corpo, associada às funções que integram a personalidade e assim auxilia, definitivamente, a formação da criança. Desde o princípio até o fim, a aprendizagem passa pelo corpo.

A Educação Física atuando na formação e na construção do conhecimento do educando, trabalhando em conjunto com as demais disciplinas, pode apontar novas possibilidades de ensino por meio de um trabalho interdisciplinar. Ferreira (2006) evidencia que a esta disciplina ao se relacionar com as demais disciplinas do currículo escolar, por meio de suas especificidades, pode contribuir para a melhoria da aprendizagem de forma significativa.

Sendo assim, apontamos a necessidade da superação da fragmentação do conhecimento que encontramos na educação da criança, por meio do diálogo entre os saberes e, com certeza, da ação docente, no sentido de rever conteúdos, métodos, processos, apoiados em fundamentos consistentes, na busca de uma nova forma de ensinar e aprender. Pensamos uma Educação Física que esteja preocupada com a articulação de todas as capacidades do aluno, que valorize a sensibilidade, a descoberta, e por meio de práticas coletivas (diferentes), interdisciplinares, contribuía de forma relevante para o processo de desenvolvimento da criança.

A criança pequena vive um estágio de exploração do mundo por meio do movimento de seu corpo. Querer reprimir esse entusiasmo em nome da educação, exigindo imobilidade, silêncio e empobrecimento das atividades lúdicas e espontâneas, significa privar a criança de seu meio de desenvolvimento mais autêntico. Sua motricidade!

O movimento do corpo sugere vida, um pulsar, um respirar, um percorrer caminhos. Caminhos necessários na formação da criança, caminhos que passam pelo corpo; e chegam à mente. Mente que pensa, se expande, se modifica, socializa e evidencia a "APRENDIZAGEM", categoria aberta desvelada pelos sujeitos de nosso estudo e que coroa todas as outras categorias encontradas no caminhar e no construir interdisciplinaridade.

O exercício do aprender ocorre quando são considerados todos os aspectos de vivência e realidade da criança. Tudo que faz parte da sua vida, do seu entorno. Assim, nossos sujeitos evidenciam que a interdisciplinaridade da Educação Física na educação infantil colabora para o desenvolvimento do aprender das crianças.

Os educadores entrevistados mostram que a Educação Física 
apresenta-se como caminho para fazer essa interdisciplinaridade na Educação de Infância. Evidenciam, em suas falas, possibilidades dessa disciplina promover a interação entre os professores na busca pela superação de seus problemas, num caminho lúdico, por meio da motricidade da criança, favorecendo seu aprender.

Ferreira (2007) nos aponta que é importante perceber a Educação Física como um instrumento facilitador da aprendizagem, entendendo os conteúdos propostos em sentidos, significados e intenções, estabelecendo relações nas suas diversas dimensões: cognitiva, afetiva, social e, claro, motora. A autora pensa em um trabalho em que intenções, raciocínio e planos de ações sejam elaborados; em que as atividades tenham significado concreto, mais próximo do real e que desperte o interesse daquele que é a peça importante no processo: o aluno.

Mas, para isso, assim como não se pode pensar num sujeito fragmentado, as ações, para se tornarem eficazes, devem ser interdisciplinares. Não se pode pensar numa intervenção isolada; os conteúdos disciplinares devem se entrelaçar em um único contexto: o aprender. Não basta também que só se integrem os conteúdos; a postura interdisciplinar envolve uma determinada forma de conceber e se relacionar com o conhecimento produzido. Deve haver um relacionamento ativo e crítico de professores, alunos e conhecimentos, logo o envolvimento é condição para a prática da interdisciplinaridade. (FERREIRA, 2007).

Destarte, pensamos que a Educação Física possibilita inter-relações entre os elementos constitutivos da educação da criança. O movimento, a escrita, a atividade lúdica, a leitura, ciências, matemática, entrelaçam-se em possibilidades de interdisciplinaridade, de transformar a ação do educador, em jogos e brincadeiras que contemplem o desenvolvimento da criança em sua totalidade.

Ao pensarmos a educação física e a interdisciplinaridade na educação de infância propomos um encontro dos seres e dos saberes, atributo do humano, da atitude de ser e tornar-se, buscando ultrapassar os limites impostos pela segmentação do conhecimento, resgatando possibilidades de fazer o novo, o diferente.

\section{Referências}

ALMEIDA, Paulo Nunes. Educação lúdica. São Paulo: Loyola, 1998.

BRASIL. MEC. Secretaria de Educação. Integração das 
instituições de educação infantil aos sistemas de ensino: um estudo de caso. Brasília: MEC / SEF, 2002.

CARVALHO, Patrícia Alves. Retocando a aprendizagem na educação de infância: a música como linguagem. Dissertação de Mestrado. Campo Grande: UFMS, 2004.

COSTA, Auredite Cardoso. P s i copedagogia e Psicomotricidade: Pontos de interscção nas dificuldades de aprendizagem. Rio de Janeiro: Vozes, 2001.

FAZENDA, I. C. A. (Org.). (Org.). Didática e interdisciplinaridade. 11 ed. Campinas, SP: Papirus, 2006a. (Coleção Práxis). . Interdisciplinaridade : História Teoria e Pesquisa. 13. ed. Campinas, São Paulo: Papirus, 2006b. (Coleção Magistério: Formação e Trabalho Pedagógico).

In t e gração e interdisciplinaridade no ensino brasileiro: efetividade ou ideologia? 5. ed. São Paulo: Loyola, 2002. (Coleção Realidade educacional-IV).

FERRAZ, O. L; MACEDO, L. Educação física na educação infantil do município deSãoPaulo: Diagnóstico e representação curricular em professores. Revista Paulista de Educação Física. São Paulo, v.15, n.1, p. 63-82, jan/jun. 2001.
FERREIRA, Vanja. Educação Física: interdisciplinaridade, aprendizagem e inclusão. Rio de Janeiro: Sprint, 2007.

LIMA, Valéria Sperduti. Lingugem. In: FAZENDA, Ivani Catarina Arantes (Org.). Dicionário em construção: Interdisciplinaridade. 2. ed. São Paulo: Cortez, 2002a.

MATTOS, Mauro Gomes de; NEIRA, Marcos Garcia. Educação Física infantil: Inter-relações: movimento, leitura, escrita. 2. ed. São Paulo: Phorte, 2007.

MERLEAU-PONTY, Maurice. Fenomenologia da percepção. 3. ed. São Paulo: Martins Fontes, 2006a.

. Psicologia e pedagogia da criança: curso da Sourbone 1949-1952. São Paulo: Martins Fontes, 2006b.

RICOEUR, Paul. Teoria da interpretação. $O$ discurso e $\mathrm{O}$ excesso de significação. Lisboa Portugal: Edições 70, 1976.

ROSA, Sanny S. Construtivismo e mudança. 3. ed. São Paulo, Cortez, 2002.

TANI, G. Educação física na educação infantil: pesquisa e produção do conhecimento. Revista Paulista de Educação Física. São Paulo, supl. 4, p.110105, 2001.

Recebido: 13/fevereiro/2010. Aprovado: 25/abril/2010. 